\title{
PERSISTENT ORGANIC POLLUTANTS (POPS) IN ANTARCTICA: CHLORINATED PESTICIDES, PCBS AND PAHS IN BLUBBER OF SEABIRDS FROM KING GEORGE ISLAND, ANTARCTICA http://dx.doi.org/10.4322/apa.2014.006 \\ Satie Taniguchi $^{1 *}$, Rosalinda C. Montone ${ }^{1}$, Marcia C. Bicego ${ }^{1}$, Jose L. Sericano ${ }^{2}$
}

\begin{abstract}
1 Universidade de Sao Paulo, Instituto Oceanografico, São Paulo, SP, Brazi
${ }^{2}$ Texas A\&M University, Geochemical and Environmental Research Group *e-mail: satie@usp.br
\end{abstract}

Persistent organic pollutants (POPs) and polycyclic aromatics hydrocarbons (PAHs), were found in preserved blubber samples from Skuas (Catharacta antarctica) and three species of Penguins (Pygoscelis adeliae, Pygoscelis papua and Pygoscelis antarctica) captured in the vicinity of the Brazilian and Polish Antarctic Stations on King George Island. Opportunistic samples of Antarctic terns (Sterna vittata), Snowy Sheatbill (Chionis alba) and Blueeyed Shag (Phalacrocorax atriceps) were also analyzed. Hexachlorobenzene (HCB), selected chlordane-related compounds, dieldrin, mirex and p,p'-DDE were the chlorinated pesticides encountered at the highest levels in all samples. On average, concentrations of chlorinated pesticides were significantly higher in skuas than in any of the other species of birds. For example, concentrations of oxychlordane, dieldrin, mirex and p,p'DDE in skuas were a factor of approximately 15, 10, 25, and 30 times higher in skuas than in penguins, respectively. Similarly, the average total concentration of PCBs was about 70 times higher in skuas than in penguins. In contrast, the concentrations of HCB were comparable in both species of birds. The much higher concentrations of POPs encountered in the blubber of skuas compared to the other species of birds included in this study can be attributed to its position in the food web as they eat fish, krill, other birds and carcasses. Total PAH contents were similar in all birds with a predominance of compounds with low molecular weight (e.g., naphthalene, 1-methylnaphthalene and 2-methylnaphthalene). The ingestion either from food or during preening is considered to be the primary source of PAHs for birds. Although PAHs are well metabolized by birds and readily excreted, they can be detected in fat depots a short period after the uptake. The detection of POPs in Antarctica wildlife, particularly those species with the greatest fidelity to the Antarctic continent (i.e., penguins) is an evidence of global dispersion of these compounds.

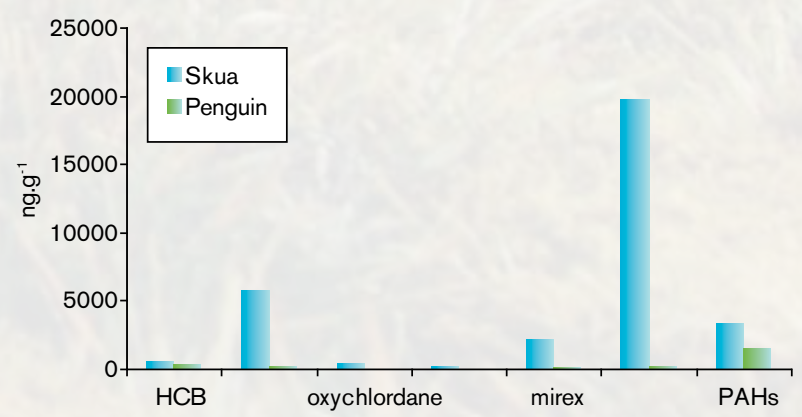

Figure 1 - Average concentrations of POPs in Antarctic seabird blubber (ng. -1 $^{-1}$

\section{Reference:}

TANIGUCHI, S. et al. Chlorinated pesticides, polychlorinated biphenyls and polycyclic aromatic hydrocarbons in the fat tissue of seabirds from King George Island, Antarctica. Marine Pollution Bulletin, v. 58, n. 1, p. 129-133, 2009. 